\title{
Methods of internal control in integrated management accounting system of the enterprise
}

\author{
A.E. Shevelev ${ }^{1}, E . V$. Sheveleva $^{1}$, and $M . Y u$. Gvozdev ${ }^{1, *}$ \\ ${ }^{1}$ South-Ural State University, Chelyabinsk, Russia
}

\begin{abstract}
The purpose of internal control procedure of material and information flows is expression of independent opinion about accounting of material and information flows of the organization, development of recommendations about elimination of detected violations and preparing data to implement automated management accounting system, based on integrated system. Internal control procedure of material and information flows in the enterprise can solve complex of problems about identifying deficiencies in accounting, searching for reserves using information resources, identifying opportunities for implementation of automated management accounting system at the enterprise. Internal control was planned and conducted thus to argue that management statements are free of misstatement, and information flows provide required operability of the entire system. Internal control was carried out on a sample basis and included examining, on a test basis evidence supporting the amounts and disclosures in management reports. The disclosure of information about innovative activities, assessment of compliance with the principles and rules of accounting used in the preparation of management reporting, the review of key performance indicators, as well as evaluating the presentation of management reports are presented.
\end{abstract}

\section{Introduction}

Implementation of integrated management accounting system using information resources, and it's further use require internal control procedure, which allows to control quality of management accounting and information resource's implementation in all responsibility centers of the enterprise.

Under conditions of crisis economicphenomena's development finding and applying of innovative types of resources - is a key issue for economic activity and further development of the enterprise. The use of information resource in the company's innovative activity and implementation of integrated management accounting system require internal control procedures and it's methods.

\section{Relevance}

To implement and operate the integrated management accounting system in the company, conducting of internal control of responsibility centres of the organization becomes an urgent problem. It allows to test the quality of management accounting and the functionality of the information resources, and also to check the consistency of accounting documentation flows and information flows between themselves.

\section{Mane Problem}

In order to effectively manage of the company it is necessary to use the integrated management accounting system. This system is focused on the company's use of information resources, increasing its potential.

The method of internal control procedure in the integrated management accounting system, which provides quality control of accounting and functionality of information resources as well as a consistency of checking records flows and information flows between them, is offered, and the term "information resource" as a set of technical, software and information flows, where the resource is known as an alternative reserve of innovative activity of the company is justified.

At the same time, innovative activity as an independent management object has its own specific characteristics. This is due, primarily, to the length of innovative activities and difficulties in forecasting and evaluation of the results effectiveness, their significant influence to the future development of the company as a whole.

Analysis of scientific publications shows that most of companies have not developed clear methods of innovative resources management and forming complete information about economic activity of a company. Lack of operational management of material and information flows makes it difficult to make management decisions and plan their further work $[1,2,3]$.

Most important types of resources:

- human resources;

- material and technical resources;

- financial resources;

- information resource. 
Today in science literature academics have recognized the crucial role of information resource in modern society. However, there are almost no works, giving a complete view of it. Many authors give a narrow interpretation of the term, referring to an information resource only information that is alienated from its creator and is fixed in a tangible medium (Godin V. V., Korneev I. K., Antopolskiy A. B., Kostrov A. V., Gendina N.I., Peshkova O.V.), scientific and technical information (Nizhegorodtsev R. M.) [4, 5, 6, 7] or expand it to an information system, which includes in addition staff (Abraham Block, Timothy D. Wells and Christine Sevilla, Bretagne, Ellen Monk, James O'Brian and George Maracas, Frank Dravis) [8, 9, 10, 11, 12, 13, 14].

In author's opinion, information resource - is a set of installed software that allows planning, accounting, control and administration of the whole available amount of information stored on the media in databases, and technical support, including network equipment, together with the means of collection, transmission, processing and storage of information, and existing information flows between responsibility centers. Unlike most resources that are able to dwindle, information resources tend to be accumulated, be enriched and can be used repeatedly. These properties allow us to speak about the great potential of this type of resources that must be used to solve the strategic management problems.

Analysis of various approaches to the structure of information resource of the company, allows to determine the following types:

- computer equipment and communication equipment;

- licensed software and auto-trade information system;

- the totality of data and documents in libraries, archives, funds, databases, etc., as well as the electronic and print media;

- local area network, the Internet, an information portal.

Typically, companies possess all these types of resources, which together form total information. The use of information resource and forming an integrated management accounting system on its basis, will allow to solve problems of information support and automation of innovative activity management.

Currently problems of taking various automated control systems are widely discussed. Such systems should provide high efficiency of the management to improve the speed and quality of information flows.

Overview of publications on the subject shows a trend of using automated management systems.

Successful western companies which have implemented these technologies can be an example for Russian companies. Many companies develop their own certain fragments of automated systems to solve current problems. Comprehensive implementation of these activities will provide integration of the information resources and will allow creating information infrastructure according to current organizational structure and current flows [15].

Analysis of the publications about automated systems implementation allows us to characterize this process as quiet complex. The main difficulty is to implement and form the management system. In this case, you must adjust this system for existing management processes in the company. It impose a number of restrictions on the automated system and greatly reduces its effectiveness. Sometimes developers have problems that can not be solved, so we have to accept a compromise, or refuse it's further implementation. Such difficulties mainly caused by the lack of opportunities to automate certain management processes [16].

To successful implementation of the integrated management accounting system in the company accuracy measures of internal control of flows existing should be made.

Category of accounting flows, in our view, includes activity indicators, that will reflect the nature of the financial and non-financial activities.

Internal control of accounting and informational flows is a complex event, which can be divided into two components:

- control of account flows;

- control of information flows.

To achieve this goal must be solved following problems:

- to determine compliance with the accounting rules of the selected resources;

- to check the documentation schedule and it's compliance;

- to assess existing information resources of the company;

- to identify accounting deficiencies in various automated accounting systems while their interaction.

Developed methods of internal control in company is presented in the form of a block diagram (Fig. 1).

For successful control of accounting and information flows they should be presented in the form of diagrams. Based on these diagrams, one can define options for interaction and information flows using.

Before using the automated management accounting system it is necessary to understand what management accounting data are receiving at the moment, what information system they are received from, what information system contains the most reliable accounting data and in what form that information is supplied to the managers.

This diagram describes the methods of internal control of accounting information flows in the company. Methods of internal control of each responsibility center of the company includes:

- check of management accountingquality. It includes check of accounting data accuracy, formed by responsibility centers and it's moving between them. At this stage accounting data is assessed for compliance to legislative and internal requirements, appropriateness of data forming, lack of duplication, availability of a responsible person, compliance to document circulation schedule. In case of shortcomings adjustments should be done. Then formation of accounting data flows is compiled;

- check of information resource functionality. It is necessary to evaluate if management accounting system is provided with automated tools. 


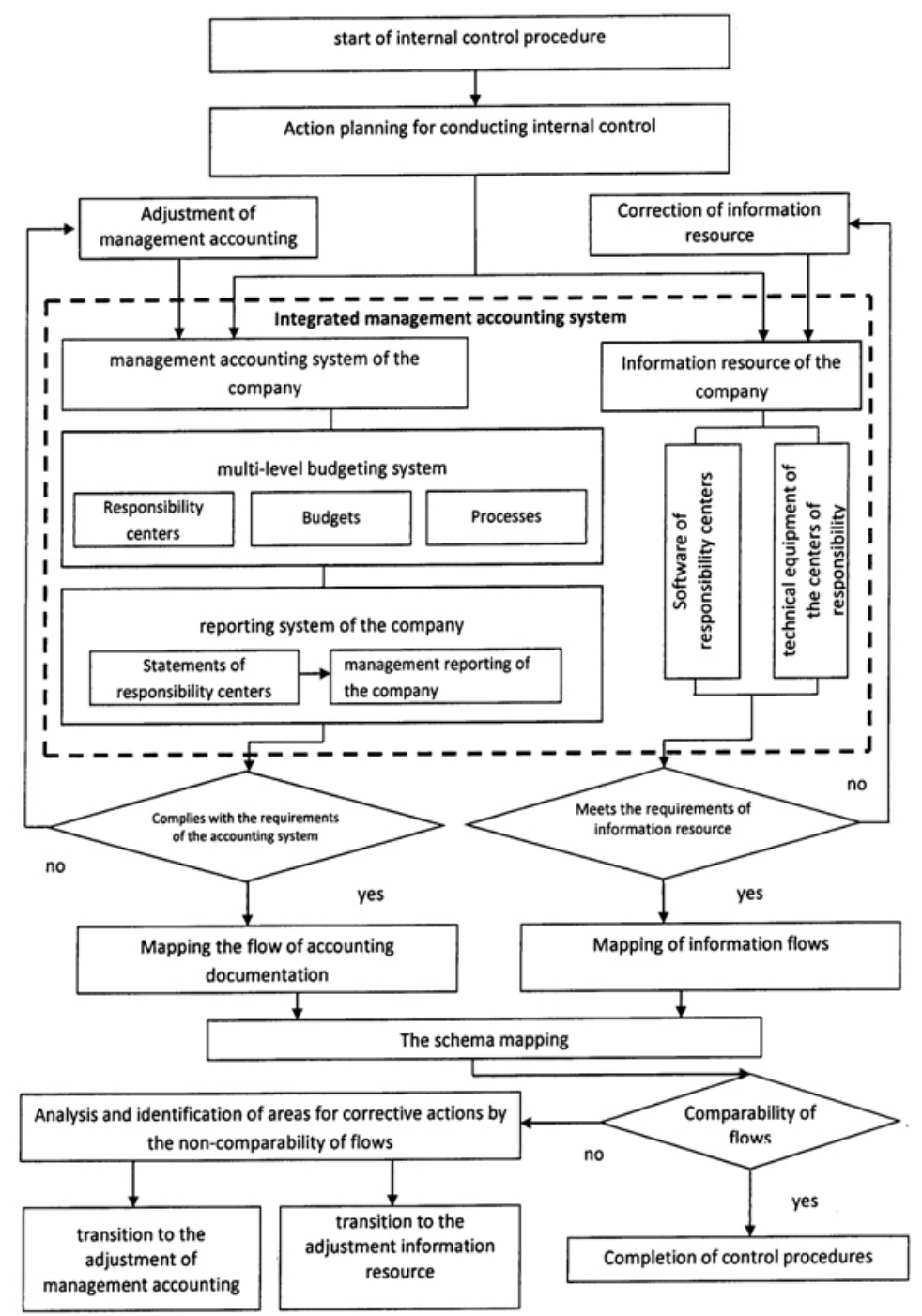

Fig. 1. Methods of internal control in integrated management accounting system of the enterprise.

- check of operability of existing automated systems, their ability of further modernization in accordance with the objectives of management accounting and electronic data transfer method, the presence and movement of data flows. When shortcomings are found, corrective actions are carried out and all defects of information flows formation of using precut software are eliminated.

- flow charts of data and information flows between the centers of responsibility are prepared. It is necessary to evaluate all information, which passed between the responsibility centers and what information systems are most reliable and technically provided, etc.;

- check of consistency of accounting and information flows between themselves. Scheme are compared and flows provision of accounting information are evaluated (possibility to transfer documents in electronic form, data transmission between various kinds of program support, lag or advance of the transmitted data, etc.). In case of flows misalignment some corrective action should be taken. It identifies responsibility centers; causing misalignment inside the center of responsibility(management accounting system and/or information resource), and correction of such sources is performed. Integrated system of management accounting becomes a result of internal control.
Internal control is carried out while planning and implementation of integrated management accounting system, and periodically during its use in cases of changes in management accounting system (changes in legislation, changes in reporting requirements, etc.) and information resource (new software, new devices, etc.).

To assess compliance with the rules of accounting of inventories, you can use the methodical instructions on accounting of inventories (further - Methodical instructions on accounting of inventories) [17].

Legal documents on the organization of information flows in the higher school in the Russian Federation are not developed yet [18]. Therefore, the order of information data transmission needs to be determined by the company. Data transfer is determined by the internal standards and regulations.

There are quite a number of sources normativelegislative regulation on accounting of material flows that need to be followed by relying organization or individual person during the audit. However, information flows control is a fairly recent trend in the Russian practice, therefore, principles of rationality and efficiency should be applied [19]. 
Under conditions of innovative activity the question of timely information receipt about real situation in the centers of responsibility, as well as about accurate and reliable information of company's activities and liabilities, sharply raises. However, before implementation of integrated management accounting system it is necessary to ensure in correct accounting and information flows organization. For these purposes it is necessary to conduct internal control. This direction is quite new for Russian companies and certain methods have not developed yet.

The joint consideration of flow charts allows to judge about the quality of management accounting and traffic of information flows between centers of responsibility. This procedure is necessary as part of the integration process of convergence of management accounting and information resource, in order to obtain integrated management accounting system. Internal control excludes the replication of the negative factors, accounting factors, accounting informational flows to in the prospective budgeting system and identifies shortcomings of the existing information resource. Thus, follow-up actions for the implementation of elements of management accounting system will be provided with an efficient structure of center of responsibility, and reliable instrument as an information resource of the company.

\section{Conclusion}

In conclusion, we can draw the following conclusions:

- internal control conducting provides an opportunity to ensure that the accounting and movement of data in the company are conducted in accordance with established rules, which in turn is a prerequisite for the introduction of an integrated managerial accounting system;

- internal control of information flows reveals the presence or absence of required traffic, as well as shortcomings in data transfer organization between centers of responsibility in the company;

- joint consideration of scheme of data and information flows movement allow to determine the causes of the poor functioning of the entire management structure of the company.

Internal control was planned and conducted thus to argue that management statements are free of misstatement, and information flows provide required operability of the entire system. Internal control was carried out on a sample basis and included examining, on a test basis evidence supporting the amounts and disclosures in management reports. The disclosure of information about innovative activities, assessment of compliance with the principles and rules of accounting used in the preparation of management reporting, the review of key performance indicators, as well as evaluating the presentation of management reports are presented. Authors believe that the internal control provides sufficient information about the reliability of management reporting, identifies the features of the topology information and resource of functioning of information flows.

Thus, when information and material control is conducted, complex problems of identifying limitations of accounting, searching of reserves for accounting optimization, definition of automated system configuration of management accounting are solved.

Conclusions and proposals presented in the thesis, have been successfully used in the activities of the office of scientific research, the development of the information portal of the innovation resources of the University in the field of energy and resource saving http://itou.susu.ac.ru/ [20].

The work was supported by Act 211 Government of the Russian Federation, contract № 02.A03.21.0011.

\section{References}

1. B. Needles, H. Anderson, D. Goldwell, Accounting, 6, 9, 11, 12 (1991)

2. Y.V. Sokolov, Accounting, 18 (2000)

3. A.D. Sheremet, Complex economic analysis of enterprise activity (methodology) (Economic, Moscow, 2012)

4. V.V. Godin. I.K. Korneev, Information resources management (UNITI, Moscow, 2000)

5. A.B. Antopolskiy, V.I. Aussem, S.A. Blau, A.I. Gegel, Research and development of metadata for electronic information resources and services in fundamental science. www.inforeg.ru.

6. N.I. Gendina, Bibliospere: quarterly scientific journal, 1, 88-89 (2011)

7. O.V. Peshkova, Series of applied Informatics, 53, 2335 (2014)

8. L. Stanton, Proc. of 10-th International Conference of European University Information Systems ENUS, 4245 (2008)

9. Shtub Avraham, Enterprise resource planning the dynamics of operations management (By Kluwer Academie Publihcis, 1999)

10. D. Wells Timothy, Christine Sevilla, Maximizing the Enterprise Information Assets (N.W. Corporate Beld, Buch Raton, Florida, 2000)

11. P. Karpova, Managementaccounting: textbook for high schools (UNITI, Moscow, 2003)

12. Ellen Monk, Concepts in Enterprise Resource Planning (2005)

13. R.Y. Wang, S. Madnick, Journal of Management Information Systems, 5, 2, 5-2 (1988)

14. E.E. Lavrisceva, Reproduction: the interrelationship of political-economic and institutional aspects, 56-67 (2010)

15. V.V. Krukov, Proc. Information and communication technologies in education and scientific activity, Novorossiysk, 42-48 (2008)

16. M.V. Ievenko, University, 1, 96-104 (2008)

17. The plan of bookkeeping accounts of financial and economic activities of organizations and instructions for its use (approved by the order of Ministry of Finance no. 94)

18. Management of information flows in the enterprise. $\mathrm{http} / / /$ roscomtech.ru/it-services/it-consulting/123.

19. $\mathrm{http}: / / \mathrm{ems} . \mathrm{ru} / 1 \mathrm{c} /$ ?inc=1c-buhgalteriya- 8 .

20. http://itou.susu.ac.ru. 